\title{
SEISMIC HAZARD ASSESSMENT FOR THE CORINTH GULF AND CENTRAL IONIAN ISLANDS BY MEANS OF THE LINKED STRESS RELEASE MODEL
}

\author{
Mangira O. ${ }^{1}$, Papadimitriou E. ${ }^{1}$, Tsaklidis G. ${ }^{2}$, Vasiliadis G. $^{3}$ \\ ${ }^{1}$ Aristotle University of Thessaloniki, Department of Geology, 54124, Thessaloniki, Greece, \\ omamgira@geo.auth.gr, ritsa@geo.auth.gr \\ ${ }^{2}$ Aristotle University of Thessaloniki, Department of Mathematics, 54124, Thessaloniki, Greece, \\ tsaklidi@math.auth.gr \\ ${ }^{3}$ TEI of West Macedonia, Department of Informatics Engineering, 52100, Kastoria, Greece \\ gvasil@math.auth.gr
}

\begin{abstract}
Earthquake generation causes spatio-temporal stress changes on adjacent fault segments that can alter the occurrence probability of subsequent earthquakes onto them. The interaction is investigated with the Linked Stress Release Model, applied to fit historical data from two areas that accommodate high seismicity, the Corinth Gulf and the Central Ionian Islands. These two areas are divided in two subareas, based on seismotectonic features; Corinth Gulf is divided in the western and eastern part, whereas the area of Central Ionian Islands is divided in Kefalonia and Lefkada subareas. The results establish interactions between the subareas, especially in the Central Ionian Islands, and underline the differences in tectonic structures and earthquake mechanisms between these areas. Particularly, the seismicity in the Central Ionian Islands is proved to be more complex and active and yet more difficult to be examined, whereas the LSRM fits the Corinth Gulf data more easily.

Keywords: interaction, point process, conditional intensity function.
\end{abstract}

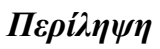

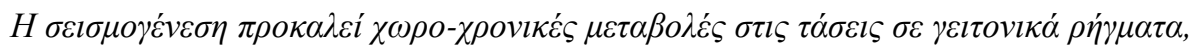

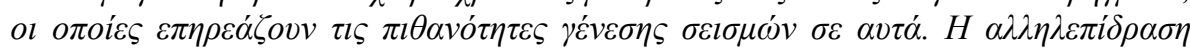

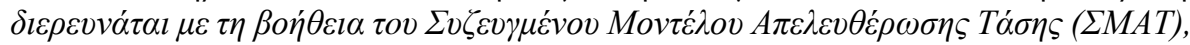

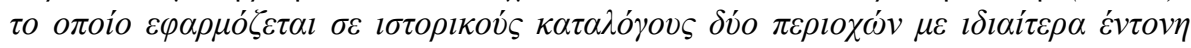

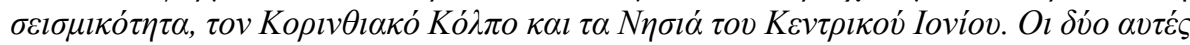

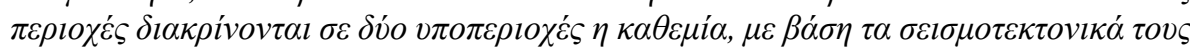

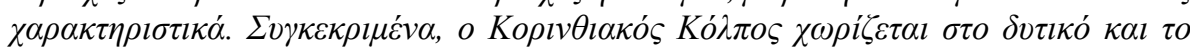

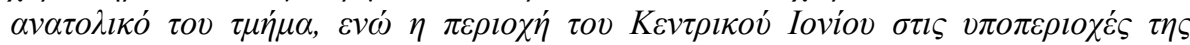

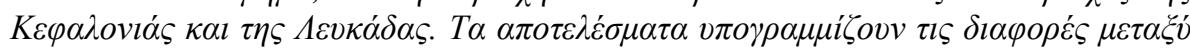

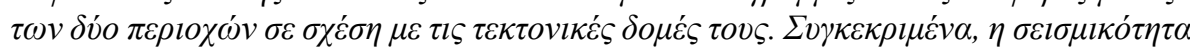

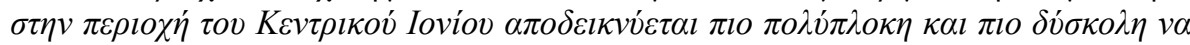

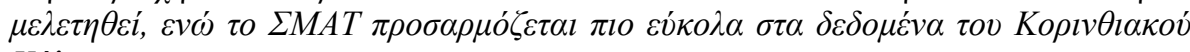

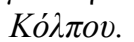

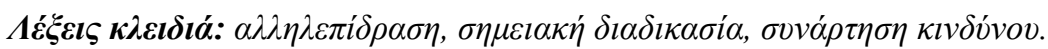




\section{Introduction}

Considerable efforts were exerted during the last decades for evaluating the seismic hazard in a region by means of the stress release models. Vere-Jones and Deng (1988) and Zheng and Vere-Jones (1991, 1994) were the first to apply and study in detail the Simple Stress Release Model (SRM), a stochastic version of the elastic rebound theory. According to the models based on this theory, a large earthquake should be followed by a period of quiescence. Kagan and Jackson (1991) though, suggest a long-term, weak clustering which characterizes all the mainshocks and Gabrielov and Newman (1994) support that a strong earthquake can be followed by a period of activation and sometimes other earthquakes of comparable magnitude. This kind of behavior could be explained through stress transfer between different regions. Liu et al. (1999) proposed the Linked Stress Release Model (LSRM) introducing stress interaction between different parts of a region to estimate the effect on the seismic hazard in each part. Ever since, stress release models have been applied to historical earthquakes from different regions worldwide (e.g. Lu et al., 1999; Lu and Vere-Jones, 2000; Bebbington and Harte, 2001, 2003; $\mathrm{Lu}, 2005$ ) or to synthetic earthquake catalogs (Lu and Vere-Jones, 2001). More recently, information gains and entropy scores have been used for scoring probability forecasts (Bebbington, 2005; Harte and Vere-Jones, 2004), whereas Rotondi and Varini (2006, 2007) analyze stress release models from the Bayesian viewpoint.

In this paper, we model the earthquakes occurrence as a stochastic point process by applying LSRM to the historical earthquake catalogs from the Corinth Gulf and the Central Ionian Islands focusing on the stress transfer among subareas of these two areas. The results obtained, confirm interactions between the subareas, especially in the Central Ionian Islands, and yet underline the differences in tectonic structures between the two study area.

\section{Study areas}

The study areas were extensively investigated during the last decades since they have experienced several destructive earthquakes and have been identified as sites of major importance for earthquake studies in Europe. The rift of Corinth consists one of the most prominent active structures, which separates continental Greece from the Peloponnese (McKenzie, 1978). The high level of seismicity is testified by the historical as well as the instrumental records, which include several moderate to large earthquakes ( $M \geq 6.0$ ). In the Gulf of Corinth though, the largest magnitude observed or ever reported is hardly any greater than 6.8 , a fact that probably reflects the lack of continuity of fault segments (Jackson and White, 1989). One more feature that should be taken into account in seismic hazard studies is the earthquake occurrence very close in time (e.g. the sequence of 1981 earthquakes in the eastern part of the Corinth Gulf).

The central Ionian Islands area, which includes Lefkada and Kefalonia Islands, constitutes the most active part of shallow seismicity in the broader Aegean region, exhibiting the highest seismic moment rate $\left(>10^{25}\right.$ dyn $\mathrm{cm} \mathrm{yr}^{-1}$, Papazachos et al., 1997). The Kefalonia Transform Fault Zone (KTFZ) has been recognized as responsible for the high levels of seismicity in the region, connecting the continental collision to the north with the oceanic subduction to the south. Seismicity is mainly concentrated along the west shoreline and offshore of the two Islands, with almost all the $M \geq 6.0$ events to be associated with the fault segments that are part of KTFZ. Lefkada Island has suffered many times from earthquakes occurring in the nearby Kefalonia Island, a fact that suggests possible coupling between the Lefkada and Kefalonia faults (Papadimitriou, 2002). Therefore, it is particularly interesting to examine the interactions between earthquakes occurring in each subarea via stress release models. Votsi et al. (2011) were the first to apply these models to central Ionian Islands. Two different datasets are used in their study, one comprising earthquakes with $M \geq 6.0$ that covers the period 1862-2008 and one comprising earthquakes with $M \geq 5.2$ that covers the period 1911-2008, used in order to obtain a complete catalog with more data necessary for the application of the LSRM. The division between the subareas of Kefalonia and Lefkada is slightly 
different than the one chosen in this study, as well as the dataset used (period selected, magnitude cut-off).

Due to the large number of parameters of the models used, as it will be shown in the methodology section, a large data sample is required. The data used for the current study are taken from the catalog compiled from the Geophysics Department of Aristotle University of Thessaloniki (http://geophysics.geo.auth.gr/ss/). We need though to compromise the fact that we are interested in the strong earthquakes that occurred in both regions. Thus, an effort is made to obtain the largest and longest possible complete earthquake catalog, which in the case of the Corinth Gulf is the one comprising earthquakes with magnitude $M \geq 5$.0 that occurred in the area since 1911 and in the case of the Ionian Islands earthquakes magnitudes with $M \geq 5.2$ for the same period. The temporal distribution of the events is shown in Figures 1 and 2, respectively. Since we will apply the LSRM, the two areas were further divided into two subareas according to their seismotectonic features; the Corinth Gulf is divided in the western and eastern part, whereas Central Ionian Islands are divided in the subatreas of Kefalonia and Lefkada.

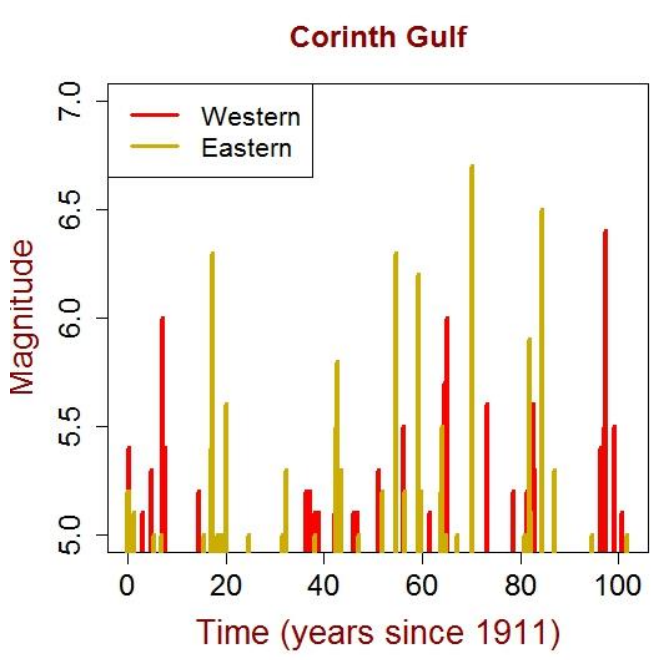

Figure 1 - Temporal distribution of the earthquakes with $M \geq 5.0$ that occurred in the Corinth Gulf since 1911.

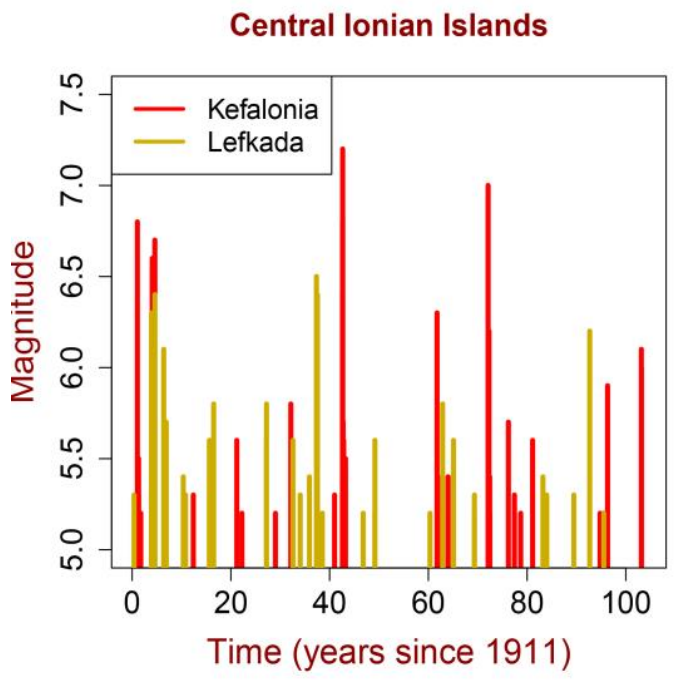

Figure 2 - Temporal distribution of the earthquakes with $M \geq 5.2$ that occurred in the Central Ionian Islands since 1911.

\section{Stress Release Models}

\subsection{Simple Stress Release Model (SSRM)}

In the Simple Stress Release Model, the key variable is the stress level in a region, which determines the probability of an earthquake to occur (Vere-Jones and Deng, 1988). The evolution of stress $X(t)$ as a function of time, could be written as

$$
X(t)=X(0)+\rho t-S(t)
$$

where $X(0)$ is the initial stress value, $\rho$ is the loading rate and $S(t)$ is the accumulated stress release from earthquakes within the area over the period $(0, t)$, i.e.,

$$
S(t)=\sum_{t_{i}<t} S_{i},
$$

where $t_{i}, S_{i}$ are the time and the stress release, respectively, associated with the $i$-th earthquake. 
The amount of stress released by an earthquake can be estimated from empirical relations as a function of its magnitude. Kanamori and Anderson (1975) show that the magnitude $M$ is proportional to the logarithm of the seismic energy released according to the relation $M=2 / 3 \log E+$ const. Bufe and Varnes (1993) suggest the cumulative Benioff strain as a measure of the total energy released, i.e., $S(t)=\sum_{i=1}^{N(t)} E_{i}^{1 / 2}$, where $E_{i}$ is the seismic energy of the $i$-th earthquake and $N(t)$ stands for the number of earthquakes till time $t$. Then we have the relation

$$
S=10^{0.75\left(M-M_{\min }\right)},
$$

where $M$ denotes the earthquake magnitude and $M_{\min }$ the normalized magnitude.

The stochastic behavior of the model is characterized by the conditional intensity function, which is equal to the hazard function and it is assumed to have the exponential form

$$
\lambda^{*}(t)=\Psi(X(t))=\exp [\mu+v(X(0)+\rho t-S(t))]=\exp [a+v(\rho t-S(t))]=\exp \{a+b[t-c S(t)]\} .
$$

Estimation of the parameters is performed numerically by maximizing the log-likelihood function

$$
\log L=\sum_{i=1}^{N(T)} \log \lambda^{*}(t)-\int_{0}^{T} \lambda^{*}(u) d u,
$$

where $(0, T)$ is the observational interval and $N(T)$ is the total number of events in $(0, T)$.

\subsection{Linked Stress Release Model (LSRM)}

From the above description, it can be seen that stress transfer is not taken into account in the Simple Stress Release Model. In order to incorporate interactions between different subareas, the Linked Stress Release Model is proposed. In that case, the evolution of stress in the $i$-th area can be rewritten as

$$
X_{i}(t)=X_{i}(0)+\rho_{i} t-\sum_{j} \theta_{i j} S(t, j),
$$

where $S(t, j)$ stands for the accumulated stress release in the subarea $j$ over the period $(0, t)$ and the coefficient $\theta_{i j}$ measures the fixed proportion of stress drop, which is transferred from subarea $j$ to subarea $i$. It is plausible to set $\theta_{i i}=1$. Positive and negative values of $\theta_{i j}$ indicate damping and excitation respectively.

We assume that each area has an exponential hazard function and we obtain for each area $i$ a conditional intensity function of the form

$$
\lambda_{i}^{*}(t)=\Psi\left(X_{i}(t)\right)=\exp \left\{\alpha_{i}+v_{i}\left[\rho_{i} t-\sum_{j} \theta_{i j} S(t, j)\right]\right\},
$$

where $\alpha_{i}\left(=\mu_{i}+v_{i} X_{i}(0)\right), v_{i}, \rho_{i}$ and $\theta_{i j}$ are the parameters to be fitted. A simpler parameterization (Liu et al., 1998) is achieved by setting $b_{i}=v_{i} \rho_{i}$ and $c_{i j}=\theta_{i j} / \rho_{i}$, yielding

$$
\lambda_{i}^{*}(t)=\exp \left\{a_{i}+b_{i}\left[t-\sum_{j} c_{i j} S(t, j)\right]\right\},
$$

where $a_{i}, b_{i}, c_{i j}$ are the parameters to be fitted for each subarea $i$.

For the estimated parameters there are some restrictions that should be taken into account. The parameters $b_{i}=v_{i} \rho_{i}$, אal $c_{i l}=1 / \rho_{i}$ should be positive, since the loading rate $\rho_{i}$ and the sensitivity to stress change, $v_{i}$, take (only) positive values. On the contrary, $c_{12}$ and $c_{21}$ could take either positive or negative values.

Estimates of the parameters are found by numerically maximizing the log-likelihood 


$$
\log L=\sum_{i=1}^{N_{1}(T)} \log \lambda_{1}^{*}\left(t_{i}\right)+\sum_{j=1}^{N_{2}(T)} \log \lambda_{2}^{*}\left(t_{j}\right)-\int_{0}^{T}\left(\lambda_{1}^{*}(u)+\lambda_{2}^{*}(u)\right) d u,
$$

where $N_{1}(T), N_{2}(T)$ are the total number of events that occurred in the subareas 1 and 2, respectively, in the time interval $(0, T)$, spanned by our catalogs.

\section{Application of the LSRM}

\subsection{Application of the LSRM to the area of Corinth Gulf}

Zheng and Vere-Jones $(1991,1994)$ found that large geographical areas give better fits to the simple stress release model when divided into subunits. We will apply the Linked Stress Release Model in order to investigate coupling between the two subareas in the Corinth Gulf, i.e., its western and eastern parts of the Corinth Gulf.

In addition to the restrictions mentioned above, in section 3.2, geodetic data analysis shows differences in extension rates between the western $(15 \mathrm{~mm} / \mathrm{yr})$ and eastern part $(10 \mathrm{~mm} / \mathrm{yr})$ of the Corinth rift (Briole et al., 2000; Chousianitis et al., 2015). There are then additional restrictions concerning the loading rates. Particularly, by allowing $\rho_{1} / \rho_{2}=3 / 2$, we get $c_{11} / c_{22}=2 / 3$. The maximum value of the $\log$-likelihood function is $\log L=-167.266$ and is calculated numerically through a Newton-type algorithm. The standard errors are calculated by means of the Fisher information matrix. The parameters $b_{i}$ and $c_{i i}$, which have to be positive, were transformed via an exponential transformation in order for the confidence intervals to include only positive values. The parameters we derived through the MLE method are presented in Table 1.

Table 1 - Estimated parameters, standard errors and $90 \%$ confidence intervals for the LSRM applied to the Corinth Gulf.

\begin{tabular}{|c|c|c|c|}
\hline Parameter & Estimation & Standard error & $\begin{array}{c}\text { 90\% Confidence } \\
\text { Interval }\end{array}$ \\
\hline $\mathrm{a}_{1}$ & -0.8119 & 2.0058 & $(-4.1114,2.4876)$ \\
\hline $\mathrm{a}_{2}$ & -0.7967 & 2.4102 & $(-4.7615,3.1680)$ \\
\hline $\mathrm{b}_{1}$ & 0.0149 & 0.0032 & $(0.0143,0.0153)$ \\
\hline $\mathrm{b}_{2}$ & 0.0413 & 0.0009 & $(0.0397,0.0428)$ \\
\hline $\mathrm{c}_{11}$ & 0.2513 & 0.0264 & $(0.2079,0.2947)$ \\
\hline $\mathrm{c}_{12}$ & 0.4550 & 0.0130 & $(0.4336,0.4764)$ \\
\hline $\mathrm{c}_{21}$ & 0.6112 & 0.0414 & $(0.5431,0.6793)$ \\
\hline $\mathrm{c}_{22}$ & 0.3773 & 0.0264 & $(0.3339,0.4208)$ \\
\hline
\end{tabular}

Next, we transform the aforementioned parameters in order to get $v_{i}, \rho_{i}$ and $\theta_{i j}$. The results are presented in Table 2 . 
Table 2 - Transformed parameters for the LSRM applied to the Corinth Gulf.

\begin{tabular}{|c|c|c|c|c|c|}
\hline Subarea $\boldsymbol{i}$ & $\boldsymbol{a}_{\boldsymbol{i}}$ & $\boldsymbol{v}_{\boldsymbol{i}}$ & $\boldsymbol{\rho}_{\boldsymbol{i}}$ & $\boldsymbol{\theta}_{\boldsymbol{i} \mathbf{1}}$ & $\boldsymbol{\theta}_{\boldsymbol{i} \mathbf{2}}$ \\
\hline $\begin{array}{c}\text { Western } \\
\text { Corinth (1) }\end{array}$ & -0.8119 & 0.0004 & 3.97 & 1 & 1.806 \\
\hline $\begin{array}{c}\text { Eastern } \\
\text { Corinth (2) }\end{array}$ & -0.7967 & 0.0156 & 2.65 & 1.619 & 1 \\
\hline
\end{tabular}
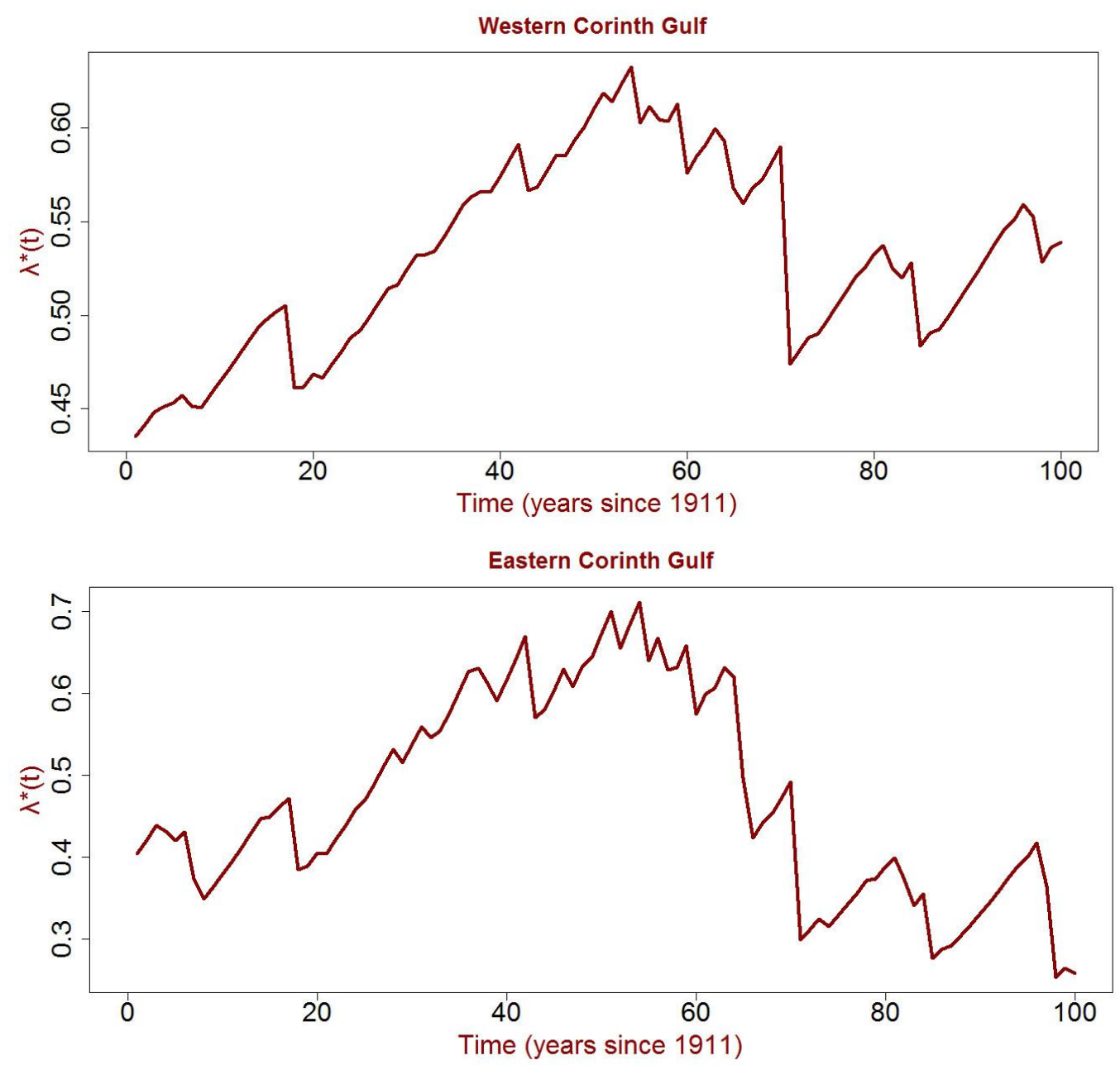

Figure 3 - The conditional intensity function versus time for each subarea calculated by the LSRM, fitted to the catalog of earthquakes with $M \geq 5.0$ that occurred since 1911. (top) western part of the Corinth Gulf. (bottom) eastern part of the Corinth Gulf.

The hazard functions calculated by using the fitted parameters are shown in Figure 3. The transformation of the parameters along with the hazard functions help us interpreting the results and the possible interactions between the two subareas. Both parameters, $\theta_{12}$ and $\theta_{21}$, are positive, which means that earthquakes occurring in the western part of the Corinth Gulf (subarea 1) can be considered to "provoke" (more precisely, "are accompanied by") damping, i.e., decrease of the occurrence rate in the eastern part (subarea 2) and vice versa. 


\subsection{Application of the LSRM to the area of Central Ionian Islands}

The LSRM is applied to the earthquakes with $M \geq 5.2$ that occurred in the Central Ionian Islands since 1911. Due to the fact that earthquakes in our data set have to be independent events, aftershocks are removed and this fact leads to a catalog of 75 events in total.

In order to find the maximum value of the likelihood function of the model the (8-dimensional) parameter space was scanned numerically using a dense grid (with step varying from 0.01 to 0.1 ), by also taking into account the restrictions of the model. The maximum value of the log-likelihood function of the LSRM applied in Central Ionian Islands is -145.6144 and is obtained for the parameters given in Table 3.

Table 3 - Linked Stress Release Model parameters for Central Ionian Islands.

\begin{tabular}{|c|c|c|c|}
\hline Parameter & Estimation & Standard error & $\begin{array}{c}90 \% \text { Confidence } \\
\text { Interval }\end{array}$ \\
\hline $\mathrm{a}_{1}$ & 0.3 & 0.0246 & $(0.2594,0.3405)$ \\
\hline $\mathrm{a}_{2}$ & 0.1 & 0.0287 & $(0.0527,0.1473)$ \\
\hline $\mathrm{b}_{1}$ & 0.04 & $2.57 * 10^{-5}$ & $(0.0399,0.0400)$ \\
\hline $\mathrm{b}_{2}$ & 0.03 & $1.84^{-5} 10^{-5}$ & $(0.0299,0.0030)$ \\
\hline $\mathrm{c}_{11}$ & 0.333 & 0.0015 & $(0.3308,0.3354)$ \\
\hline $\mathrm{c}_{12}$ & 0.8 & 0.0042 & $(0.7930,0.8070)$ \\
\hline $\mathrm{c}_{21}$ & 0.6 & 0.0035 & $(0.5948,0.6052)$ \\
\hline $\mathrm{c}_{22}$ & 0.5 & 0.0022 & $(0.4963,0.5037)$ \\
\hline
\end{tabular}

The transformed parameters are presented in Table 4.

Table 4 - Transformed Linked Stress Release Model parameters for Central Ionian Islands.

\begin{tabular}{|l|c|c|c|c|c|}
\hline Subarea $i$ & $a_{i}$ & $v_{i}$ & $\rho_{i}$ & $\theta_{i 1}$ & $\theta_{i 2}$ \\
\hline Kefalonia(1) & 0.3 & 0.0133 & 3 & 1 & 1.6 \\
\hline Lefkada (2) & 0.1 & 0.015 & 2 & 1.8 & 1 \\
\hline
\end{tabular}

The parameters are then used in order to calculate the conditional intensity functions for each subarea (figure 4).

Both parameters, $\theta_{12}$ and $\theta_{21}$ are positive (by taking the confidence intervals for the associated $c_{12}$ and $c_{21}$ into account) and thus we may argue that earthquakes occurrence in Kefalonia Island (subarea 1) "causes" (or better, "is accompanied by") damping, i.e., decrease of the earthquake occurrence rate in Lefkada Island (subarea 2) and vice versa. 

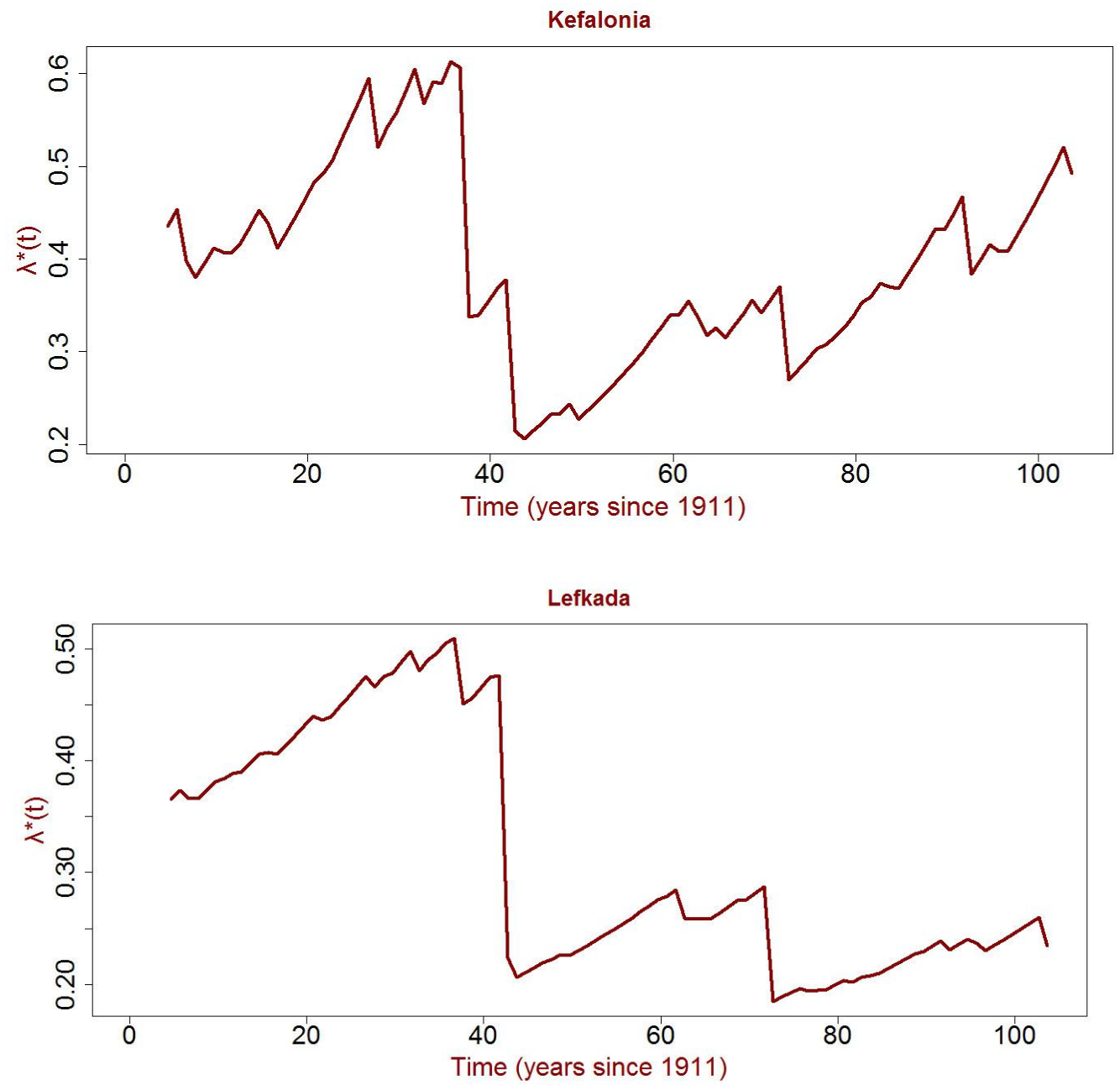

Figure 4 - The conditional intensity function versus time for each subarea of the Central Ionian Islands calculated by the LSRM, fitted to the catalog of earthquakes with $M \geq 5.2$ that occurred since 1911. (top) Kefalonia (bottom) Lefkada.

\section{Conclusions}

By means of the Linked Stress Release Model, we established a model for the interactions between different faults and yet different subareas of a larger area. The model itself provides a simple paradigm whereby spatio-temporal complexity of seismicity can be related to both the dynamics and heterogeneities in a seismic region. Large variation concerning the conditional intensity functions is observed, meaning that the risk of an earthquake occurrence is obviously not time invariant (especially in the Central Ionian Islands). This kind of behavior could be explained by the more complicated structure of this area and thus the pattern of earthquake occurrence could better be justified via the Linked Stress Release Model. Finally, it is worth noting that fitting of the LSRM leads to the conclusion that earthquake occurrences in any subarea "cause" (are accompanied by) damping, i.e., decrease of the earthquake occurrence rate in the area nearby, for both areas under study. In other words there is no evidence (using LSRM) of earthquake provoke from one subarea to the other. 


\section{References}

Bebbington, M. and Harte, D., 2003. The Linked Stress Release Model for Spatio-Temporal Seismicity, Formulations, Procedures and Applications. Geophys. J. Int, 154, 925-946.

Bebbington, M., 2005, Information gains for stress release models, Pure Appl. Geophys., 162, 22292319.

Bernard, P., Lyon-Caen, H., Briole, P., Deschamps, A., Boudin, F., Makropoulos, K., Papadimitriou, P., Lemeille, F., Patau, G., Billiris, H., Paradissis, D., Papazissi, K., Castarède, H., Charade, O., Nercessian, A., Avallone, A., Pacchiani, F., Zahradnik, J., Sacks, S. and Linde A., 2006. Seismicity, deformation and seismic hazard in the western rift of Corinth: New insights from the Corinth Rift Laboratory (CRL), Tectonophysics, 426, 7-30.

Briole, P., Rigo, A., Lyon-Caen, H., Ruegg, JC, Papazissi, K., Mitsakaki, C., Balodimou, A., Veis, G., Hatzfeld, D. and Deschamps, A., 2000. Active deformation of the Corinth rift, Greece: Results from repeated Global Positioning surveys between 1990 and 1995, J. Geophys Res., $105,25605-25625$.

Bufe, C. and Varnes, D., 1993. Predictive Modeling of the Seismic Cycle of the Greater San Francisco Bay Region, J. Geophys. Res., 98, 9871-9883.

Chousianitis, K., Ganas, A. and Evangelidis, C.P., 2015. Strain and rotation rate patterns of mainland Greece from continuous GPS data and comparison between seismic and geodetic moment release, J. Geophys. Res., 120, doi: 10.1002/2014JB011762.

Console, R., Falcone, G., Karakostas, V., Murru, M., Papadimitriou E. and Rhoades, D., 2013. Renewal models and coseismic stress transfer in the Corinth Gulf, Greece, fault system, $J$. Geophys. Res., 118, 3655-3673.

Console, R., Carluccio, R., Papadimitriou, E. and Karakostas, V., 2015. Synthetic earthquake catalogs simulating seismic activity in the Corinth Gulf, Greece, fault system, J. Geophys. Res., 120, 326-343.

Daley, D. and Vere-Jones, D., 2003. An Introduction to the Theory of Point Processes, Springer, Vol. 1, $2^{\text {nd }}$ edition, New York, 211-287.

Gabrielov, A. and Newman, W.I., 1994. Seismicity modelling and earthquake prediction: A review In Nonlinear Dynamics and Predictability of Geophysical Phenomena, Newman, W.I., Gabrielov, A. and Turcotte, D.L., eds., Am. Geophys. Union, Washington, D.C., 7-13.

Harte, D.S. and Vere-Jones, D., 2004. The Entropy Score and its Uses in Earthquake Forecasting, Pure Appl. Geophys., 162, 1229-1253.

Kanamori, H. and Anderson, D.L., 1975. Theoretical basis of some empirical relations in seismology, Bull. Seismol. Soc. Am., 65, 1073-1095.

Karakostas, V., Papadimitriou, E. and Papazachos, C., 2004. Properties of the 2003 Lefkada, Ionian Islands, Greece, earthquake seismic sequence and seismicity triggering, Bull. Seismol. Soc. Am., 94, 5, 1976-1981.

Karakostas, V., Papadimitriou, E., Mesimeri, M., Gkarlaouni, C. and Paradisopoulou, P., 2015. The 2014 Kefalonia Doublet (Mw6.1 and Mw6.0) Central Ionian Islands, Greece: Seismotectonic Implications along the Kefalonia Transform Fault Zone, Acta Geophys., 63, 1-16.

Lu, C., Harte, D. and Bebbington, M., 1999. A Linked Stress Release Model for Historical Japanese Earthquakes: Coupling among Major Seismic Regions, Earth Planets Space, 51, 907-916.

Lu, C. and Vere-Jones, D., 2000. Application of linked stress release model to historical earthquake data: comparison between two kinds of tectonic seismicity, Pure Appl. Geophys., 157, 23512364.

Lu, C. and Vere-Jones, D., 2001. Statistical analysis of synthetic earthquake catalogues generated by models with various levels of fault zone disorder, J. Geophys. Res., 106, 11115-11125.

McKenzie, D., 1978. Active tectonics of the Alpine-Himalayan Belt: the Aegean Sea and surrounding regions, Geophys. J.R. astr. Soc., 55, 217-254.

Papadimitriou, E., 2002. Mode of strong earthquake recurrence in the central Ionian Islands (Greece): Possible triggering due to Coulomb stress changes generated by the occurrence of previous strong shocks, Bull. Seismol. Soc. Am., 92, 8, 3293-3308. 
Papazachos, B.C., Karakaisis, G.F., Papadimitriou, E.E. and Papaioannou, Ch.A., 1997. Time dependent seismicity in the Alpine-Himalayan Belt, Tectonophysics, 271, 295-324.

Rotondi, R. and Varini, E., 2006. Bayesian analysis of marked stress release models for timedependent hazard assessment in the western Gulf of Corinth, Tectonophysics, 107-113.

Rotondi, R. and Varini, E., 2007. Bayesian inference of stress release models applied to some Italian seismogenic zones, Geophys. J. Int., 169,301-314.

Vere-Jones, D. and Deng, Y.L., 1988. A point process analysis of historical earthquakes from North China, Earthq. Res. China, 2,165-181.

Votsi, I., Tsaklidis, G. and Papadimitriou, E., 2011. Seismic Hazard Assessment in Central Ionian Islands Area Based on Stress Release Models, Acta Geophys., 59, 701-727.

Zheng, X. and Vere-Jones, D., 1991. Application of stress release models to historical earthquakes from North China, Pure Appl. Geophys., 135, 559-576.

Zheng, X. and Vere-Jones, D., 1994. Further applications of stress release models to historical earthquake data, Tectonophysics, 229, 101-121. 